\title{
Impact of the COVID-19 pandemic on smoking behavior and beliefs among the American University of Beirut community
}

\author{
Yasmina Al Ghadban' ${ }^{1}$ Nathalie Zgheib ${ }^{2,3}$, Maya Romani2,4, Imad Bou Akl5 ${ }^{5}$, Rihab Nasr ${ }^{2,6}$
}

\begin{abstract}
INTRODUCTION The current COVID-19 outbreak has led to sudden changes in routine and modifications in health behaviors. The study presented here investigates the changes in smoking behavior and beliefs due to the pandemic among a sample of individuals at the American University of Beirut (AUB) in Lebanon, between August and September 2020.

METHODS This is a cross-sectional exploratory study based on data collected through an anonymous, web-based questionnaire. We performed descriptive and univariate analysis on sociodemographic factors, smoking practices, smoking behavior changes, and smoking beliefs.

RESULTS In all, 197 participants (65.5\% never smokers, 8.1\% former smokers, and $26.4 \%$ current smokers) completed the online survey. Of these, $19.3 \%$ reported a change in their smoking behavior in the last four months, with an equal number of participants increasing and decreasing smoking. Univariate analysis showed that fear of contracting coronavirus and personal health concerns were significantly associated with a decrease in smoking. In contrast, the stress associated with the COVID-19 crisis and the economic crisis was associated with an increase in smoking.

CONCLUSIONS The current COVID-19 outbreak has resulted in unexpected alterations in routine and changes in health behaviors. A quarter of all participants said they had changed their smoking habits, with an equal percentage saying they had increased or decreased their smoking. Future research is needed to look into changes in smoking behavior in a more representative group.
\end{abstract}

\section{AFFILIATION}

1 School of Engineering and Applied Science, University of Pennsylvania, Philadelphia, United States 2 Cancer Prevention and Control Program, Naef K. Basile Cancer Institute, Faculty of Medicine, American University of Beirut, Beirut, Lebanon 3 Department of Pharmacology and Toxicology, Faculty of Medicine, American University of Beirut, Beirut, Lebanon

4 Department of Family Medicine, Faculty of Medicine, American University of Beirut, Beirut, Lebanon 5 Division of Pulmonary and Critical Care Medicine, Department of Internal Medicine, Faculty of Medicine, American University of Beirut, Beirut, Lebanon 6 Department of Anatomy, Cell Biology and Physiological Sciences, Faculty of Medicine, American University of Beirut, Beirut, Lebanon

\section{CORRESPONDENCE TO}

Rihab Nasr. Cancer Prevention and Control Program, Naef K. Basile

Cancer Institute and Department of Anatomy, Cell Biology and Physiological Sciences, Faculty of Medicine, American University of Beirut, 1107 2020, Beirut, Lebanon.E-mail: rn03@aub.edu.lb

\section{KEYWORDS}

smoking behavior, COVID-19, tobacco, waterpipe, smoking beliefs

Received: 28 July 2021

Revised: 30 November 2021

Accepted: 3 December 2021

\section{INTRODUCTION}

Lebanon has high smoking prevalence rates when compared to middle-income countries. The daily cigarette and waterpipe smoking prevalence rates reach $34 \%$ and $26 \%$ in males and $21 \%$ and $24 \%$ in females, respectively ${ }^{1}$. On 21 February 2021, Lebanon recorded its first case of coronavirus disease, COVID-19. A week later, in an attempt to contain the spread of the virus, schools were closed, followed by restaurants, bars, gyms, and theatres. By 15 March, the 
Lebanese government had declared a total lockdown, closed the borders, and issued stay-at-home orders ${ }^{2}$. Social distancing, health concerns, and the sudden change of routine may lead to adverse psychosocial outcomes such as stress, anxiety, depression, and increased substance use ${ }^{3,4}$. These factors have also changed people's eating habits, activity levels, and quality of sleep ${ }^{5-8}$. Similarly, containment measures may catalyze smoking behavior changes. Stress, social isolation and lifestyle changes can increase smoking behavior among smokers and relapse smoking among former smokers ${ }^{9}$. However, the pandemic may also serve as a motivator for positive health behavior changes such as a desire to reduce or quit smoking in response to a threat of infection ${ }^{10}$. In particular, the fear of smoking effects on lungs and the impact of COVID-19 on lungs might encourage smokers to improve their health and quit smoking.

Understanding smoking behavior changes is critical for effective public health interventions. To date, few studies have been published assessing the impact of the recent COVID-19 outbreak on smoking behaviors. Di Renzo et al. ${ }^{8}$ recently reported a $3 \%$ reduction in smoking due to the pandemic, whereas varying smoking changing behaviors due to COVID-19 were reported by Klemperer et al. ${ }^{11}$ with a quarter of participants reducing their cigarettes use, and more than a third motivated to quit. In an attempt to bridge this gap in the literature, the study presented here investigates the modifications in smoking behavior due to the pandemic among a sample of individuals at the American University of Beirut (AUB) in Lebanon. Given the unique situation of COVID-19 and its repercussions, we aim to explore the impact of the pandemic on smoking behaviors and beliefs.

\section{METHODS}

This is a cross-sectional study based on data collected through an anonymous, self-administered, web-based questionnaire, developed on LimeSurvey (version 3.14, Hamburg, Germany) and stored on secure AUB servers. The study aimed to assess the impact of the COVID-19 pandemic on smoking behavior and beliefs among the AUB community. The study was reviewed by the AUB Institutional Review Board (IRB) ethical committee and considered exempt (IRB ID SBS-20200236).

\section{Setting and participants}

Considering the scope and extent of the recruitment strategy, the sample included a convenience sample of AUB members (faculty, staff, and students) based in Lebanon, who agreed to participate in the study by completing the questionnaire. Eligibility criteria for the study included: 1 ) people aged $\geq 18$ years, and 2 ) ability to read English.

\section{Procedure}

The survey was opened to the public on 17 August 2020, and remained open for 23 days until 9 September 2020. The invitation to participate in the LIME survey was hosted by the AUB Office of Information Technology (AUB IT) servers. The IRB office randomly selected 1300 participants, including 500 students and 800 faculty and staff. The survey was shared in an e-mail invitation to these 1300 AUB affiliates, followed by three reminders sent a week apart. The first page of the survey contained an informed consent form. If the potential participant agreed to participate in the study, they could proceed to complete the survey. At the end of the survey, participants were redirected to a webpage hosted by the Health and Wellness Center at AUB Medical Center containing information on the smoking cessation program.

\section{Instrument}

The survey consisted of 26 questions divided among four main sections: sociodemographic factors, smoking practices, change in smoking behaviors, and beliefs about smoking and its adverse effects (Supplementary file). All questions were optional and available in English. No personal identifiers were collected.

Basic demographic data included age, gender, education level, and perceived income. Smoking practices questions included status as never smoker, former smoker or a current smoker of cigarettes, waterpipe or e-cigarettes. For current smokers, the average number of cigarettes per day, average number of waterpipes per week, and duration of smoking were collected. Questions on smoking behavior change included the direction of change (increase, decrease, start, quit) and reasons for the change. Beliefs about smoking were investigated with the following four statements: smoking negatively affects your health, smoking increases the 
risk of contracting coronavirus infection, smoking increases the severity of coronavirus infection, and smoking protects against coronavirus infection. Participants were asked whether they agreed, disagreed, or did not know. Smoking behavior questions were adapted based on the Global Adult Tobacco Survey ${ }^{12}$ and our construct and context to ensure content validity. All authors read and reviewed the contents of the survey to ensure face validity.

\section{Data analysis}

Data were exported and analyzed using Excel (v 16.30, Microsoft). Descriptive and univariate analyses were performed for sociodemographic factors, smoking practices, change in smoking behavior, and beliefs. Participants were categorized according to their reported smoking behavior, and results were reported for all participants and each of the subgroups.

\section{RESULTS}

\section{Sociodemographic characteristics}

A total of 221 AUB affiliates participated in the study resulting in a $17 \%$ overall response rate; of these, 24 participants did not complete the survey and accordingly were not included in the analysis. Therefore, 197 participants (42.6\% males and 57.4\% females) of various age groups and educational backgrounds participated in the entire survey. The majority of respondents were young, with 146 (74.1\%) being aged $<40$ years, held a university degree ( 186 ; $94.4 \%)$, and reported a medium $(116 ; 58.9 \%)$ or high income $(13 ; 6.6 \%)$. Fifty-two participants $(26.4 \%)$ were current smokers, $16(8.1 \%)$ were former smokers, and the remaining majority, 129 participants $(65.5 \%)$, were never smokers (Table 1 ).

\section{Smoking behavior}

Among current smokers, 26 participants (50.0\%) reported smoking primarily cigarettes with an average of 12.0 cigarettes per day or 219 packs per year, and 10.4 years of smoking. Nineteen participants (36.6\%) reported smoking waterpipe with an average of 3.2 per week and 10.3 years of smoking. Finally, 7 participants (13.4\%) reported smoking an average of 7.4 e-cigarettes per day for an average of 1.9 years.

Table 1. Sociodemographic characteristics of participants

\begin{tabular}{|c|c|c|c|c|}
\hline & $\begin{array}{c}A I I \\
n(\%)\end{array}$ & $\begin{array}{c}\text { Current smoker } \\
n(\%)\end{array}$ & $\begin{array}{l}\text { Former smoker } \\
n(\%)\end{array}$ & $\begin{array}{c}\text { Never smoker } \\
n(\%)\end{array}$ \\
\hline Total, $\mathrm{n}$ & 197 & 52 & 16 & 129 \\
\hline \multicolumn{5}{|l|}{ Gender } \\
\hline Female & $113(57.4)$ & $22(42.3)$ & $11(68.8)$ & $80(62.0)$ \\
\hline Male & $84(42.6)$ & $30(57.7)$ & $5(31.3)$ & $49(38.0)$ \\
\hline \multicolumn{5}{|l|}{ Age (years) } \\
\hline $18-19$ & $33(16.8)$ & $11(21.2)$ & $3(18.8)$ & $19(14.7)$ \\
\hline 20-39 & $113(57.3)$ & $30(57.7)$ & $4(25.0)$ & $79(61.2)$ \\
\hline$\geq 40$ & $51(25.9)$ & $11(21.2)$ & $9(56.3)$ & $31(24.0)$ \\
\hline \multicolumn{5}{|l|}{ Marital status } \\
\hline Single & 109 (55.3) & $31(59.6)$ & $5(31.3)$ & $73(3.9)$ \\
\hline Married/In a relationship & $88(44.7)$ & $21(40.4)$ & $11(68.8)$ & $56(96.1)$ \\
\hline \multicolumn{5}{|l|}{ Education level } \\
\hline Primary/secondary school & $11(5.6)$ & $5(9.6)$ & $1(6.3)$ & $5(5.6)$ \\
\hline University studies & $186(94.4)$ & $47(90.4)$ & $15(93.8)$ & $124(62.9)$ \\
\hline \multicolumn{5}{|l|}{ Income } \\
\hline High & $13(6.6)$ & $3(5.8)$ & 0 & $10(7.8)$ \\
\hline Medium & $116(58.9)$ & $29(55.8)$ & $11(68.8)$ & $76(58.9)$ \\
\hline Low & $48(24.3)$ & $13(25.0)$ & $5(31.3)$ & $30(23.3)$ \\
\hline None & $20(10.2)$ & $7(13.5)$ & 0 & $13(10.1)$ \\
\hline
\end{tabular}


Thirty-eight participants (19.3\%) reported a change in their smoking behavior in the last four months, with an equal number of participants increasing (19) and decreasing (19) smoking. The direction of the change was not significantly associated with any sociodemographic characteristic (data not shown). Among those who reported an increase in their smoking behavior, 6 (31.6\%) started smoking in the last four months. Among those who reported a decrease in their smoking behavior, 10 $(52.6 \%)$ quit smoking in the last four months.

Participants most frequently reported being stuck at home as a reason for their change in smoking behavior $(20 ; 38.5 \%)$, followed by stress related to the COVID-19 crisis $(17 ; 32.7 \%)$ and stress related to the economic crisis $(14 ; 28.8 \%)$. Moreover, the univariate analysis showed that fear of contracting coronavirus and personal health concerns were significantly associated with a decrease in smoking. On the other hand, stress related to the COVID-19 crisis and stress related to the economic crisis were significantly associated with an increase in smoking (Table 2).

\section{Smoking beliefs amongst smokers, former smokers, and never smokers}

The majority of participants believed that smoking negatively impacts health $(191 ; 97.0 \%)$, does not protect against coronavirus infection (152; 77.2\%), and increases the severity of coronavirus infection $(138 ; 70.0 \%)$ and the risk of contracting the virus $(113 ; 57.4 \%)$.

When looking at participants' smoking beliefs according to their smoking behavior, the vast majority of never smokers $(126 ; 97.7 \%)$, former smokers $(16 ; 100 \%)$, and current smokers (49;

Table 2. Smoking beliefs and reasons for recent change in smoking behavior

\begin{tabular}{|c|c|c|c|c|}
\hline & $\begin{array}{c}\text { All } \\
n(\%)\end{array}$ & $\begin{array}{c}\text { Decrease/quit } \\
\text { smoking } \\
n(\%)\end{array}$ & $\begin{array}{c}\text { Increase/start } \\
\text { smoking } \\
n(\%)\end{array}$ & $p^{*}$ \\
\hline Total, n & 38 & 19 & 19 & \\
\hline \multicolumn{5}{|c|}{ Reasons for recent change in smoking behavior } \\
\hline \multicolumn{5}{|c|}{ Fear of contracting coronavirus } \\
\hline Yes & $6(15.8)$ & $6(31.6)$ & 0 & \\
\hline No & $32(84.2)$ & $13(68.4)$ & $19(100)$ & 0.02 \\
\hline \multicolumn{5}{|c|}{ Personal health concerns } \\
\hline Yes & $10(26.3)$ & $9(47.4)$ & $1(5.3)$ & \\
\hline No & $28(73.7)$ & $10(52.6)$ & $18(94.7)$ & 0.008 \\
\hline \multicolumn{5}{|c|}{ Burden of increased cost } \\
\hline Yes & $9(23.7)$ & $5(26.3)$ & $4(21.1)$ & \\
\hline No & $29(76.3)$ & $14(73.7)$ & $15(78.9)$ & 1 \\
\hline \multicolumn{5}{|c|}{ Being stuck at home } \\
\hline Yes & $20(52.6)$ & $9(47.4)$ & $11(57.9)$ & \\
\hline No & $18(26.3)$ & $10(52.6)$ & $8(42.1)$ & 0.75 \\
\hline \multicolumn{5}{|c|}{ Influence of family/friends } \\
\hline Yes & $5(13.2)$ & $2(10.5)$ & $3(15.8)$ & \\
\hline No & $33(86.8)$ & $17(89.5)$ & $16(84.2)$ & 1 \\
\hline \multicolumn{5}{|c|}{ Stress related to COVID-19 crisis } \\
\hline Yes & $17(44.7)$ & $5(26.3)$ & $12(63.2)$ & \\
\hline No & $21(55.3)$ & $14(73.7)$ & $7(36.8)$ & 0.049 \\
\hline \multicolumn{5}{|c|}{ Stress related to economic crisis } \\
\hline Yes & $14(36.8)$ & $2(10.5)$ & $12(63.2)$ & \\
\hline No & $24(63.2)$ & $17(89.5)$ & $7(36.8)$ & 0.002 \\
\hline
\end{tabular}


Table 2. Continued

\begin{tabular}{|c|c|c|c|c|}
\hline & $\begin{array}{c}\text { All } \\
n(\%)\end{array}$ & $\begin{array}{c}\text { Decrease/quit } \\
\text { smoking } \\
n(\%)\end{array}$ & $\begin{array}{c}\text { Increase/start } \\
\text { smoking } \\
n(\%)\end{array}$ & $p^{*}$ \\
\hline \multicolumn{5}{|c|}{ Beliefs regarding smoking } \\
\hline \multicolumn{5}{|c|}{$\begin{array}{l}\text { Do you agree that smoking increases risk of } \\
\text { contracting coronavirus infection? }\end{array}$} \\
\hline Yes & $17(44.7)$ & 7 (36.8) & $10(52.6)$ & \\
\hline I don't know & $12(31.6)$ & $7(36.8)$ & $5(26.3)$ & \\
\hline No & $9(23.7)$ & $5(26.3)$ & $4(21.1)$ & 0.62 \\
\hline \multicolumn{5}{|c|}{$\begin{array}{l}\text { Do you agree that smoking negatively affects your } \\
\text { health? }\end{array}$} \\
\hline Yes & $37(97.4)$ & $19(100)$ & $18(95)$ & \\
\hline I don't know & 0 & 0 & 0 & \\
\hline No & $1(2.6)$ & 0 & $1(5.3)$ & 1 \\
\hline \multicolumn{5}{|c|}{$\begin{array}{l}\text { Do you agree that smoking increases the severity of } \\
\text { coronavirus infection? }\end{array}$} \\
\hline Yes & $26(68.4)$ & $16(84.2)$ & $10(52.6)$ & \\
\hline I don't know & $10(26.3)$ & $3(15.8)$ & $7(36.8)$ & \\
\hline No & $2(5.3)$ & 0 & $2(10.5)$ & 0.10 \\
\hline \multicolumn{5}{|c|}{$\begin{array}{l}\text { Do you agree that smoking protects against } \\
\text { coronavirus infection? }\end{array}$} \\
\hline Yes & 0 & 0 & 0 & \\
\hline I don't know & $10(26.3)$ & $3(15.8)$ & 7 (36.8) & \\
\hline No & $28(73.7)$ & $16(84.2)$ & $12(63.2)$ & 0.27 \\
\hline
\end{tabular}

*Two-sided Fisher exact test.

$94.2 \%$ ) agreed that smoking negatively affects health. Our analysis also showed that while the majority of never smokers $(84 ; 65.1 \%)$ and former smokers $(9 ; 56.3 \%)$ agreed that smoking increases the risk of contracting the coronavirus, only a smaller proportion of current smokers $(20 ; 38.5 \%)$ shared this belief. Similarly, a higher proportion of both former smokers $(14 ; 87.5 \%)$ and never smokers (96; 74.4\%) believed that smoking increases the severity of coronavirus infection compared to current smokers $(28 ; 53.8 \%)$. Although none of the responders believed that smoking protects against the coronavirus, a higher proportion of current smokers $(20 ; 38.5 \%)$ were unsure when compared to never smokers $(22 ; 17.1 \%)$ and former smokers $(3$; $18.8 \%)$.

\section{Smoking beliefs and change in smoking behavior}

The majority of participants believed that smoking negatively impacts health $(37 ; 97.4 \%)$, does not protect against coronavirus infection $(28 ; 73.7 \%)$, and increases the severity of coronavirus infection $(26 ; 68.4 \%)$ and the risk of contracting the virus (17; $44.7 \%)$.

When looking at participants' smoking beliefs according to their smoking behavior change, most participants who increased smoking (18; 95\%) and all participants who decreased smoking (19; $100 \%$ ) agreed that smoking negatively affects health. Our analysis also showed that while most participants who increased smoking (10; 52.6\%) agreed that smoking increases the risk of contracting coronavirus, only a smaller proportion of participants who decreased smoking ( $7 ; 36.8 \%)$ shared this belief. Similarly, a higher proportion of participants who reduced smoking $(16 ; 84.2 \%)$ believed that smoking increases the severity of coronavirus infection compared to participants who increased smoking $(10 ; 52.6 \%)$. Although none of the 
responders believed that smoking protects against coronavirus, a higher proportion of participants who increased smoking $(7 ; 36.8 \%)$ were unsure when compared to participants who decreased smoking (3; $15.8 \%$ ). In addition, the univariate analysis showed that the direction of the change was not significantly associated with any of these beliefs (Table 2 ).

\section{DISCUSSION}

This cross-sectional study was conducted among adults in the AUB community through an online $(n=197)$ survey to assess smoking practices, smoking behavior, and beliefs. This study provides a snapshot of the smoking behavior changes since the lockdown period in mid-March, in a representative sample from the AUB community.

Around a quarter of all participants reported a change in their smoking behavior, with an equal proportion of people saying they had increased or decreased their smoking. Stress from the COVID-19 and economic crises were among the highest reported reasons for smoking behavior change. Both of these reasons were more strongly associated with an increase in smoking. This is expected as high stress levels are associated with an increased prevalence of smoking ${ }^{13-15}$. While stress may increase smoking $^{16}$, stress from COVID-19 had a mixed effect on smoking behavior change in our study. For a minority of participants, stress motivated them to decrease smoking. These findings are consistent with the Health Belief Model: the pandemic and concerns about the increased risk of contraction and severity of coronavirus infection could have served as cues to engage in positive behavior modification such as decreasing smoking ${ }^{17-19}$. The mixed effect of COVID-19 on smoking behavior has also been shown in other studies ${ }^{10,20-22}$. In addition to the reasons investigated in this study, a decrease in smoking can be linked to a lack of opportunities for smokers to engage in their usual activities such as smoking at bars, while driving to and from work or university, or at gatherings ${ }^{5}$. Similarly, waterpipe is often smoked in social settings and the reduction in socialization opportunities can contribute to this decreasing trend. As a result, some participants may have decreased their smoking behavior because of a reduction in smoking opportunities and not as a motivated decision.
Despite the conflicting information in the media regarding the impact of smoking on COVID-19 in the first six months of the pandemic ${ }^{23}$, the majority of participants believed that smoking increases the risk of COVID-19 contraction and the severity of infection. However, a significantly smaller proportion of current smokers shared these beliefs. This can be explained by the fact that current smokers are more susceptible to believe that smoking has benefits during the COVID-19 pandemic because people tend to favor information that justifies their behavior ${ }^{24}$. Given the dispute over the effects of smoking behavior on COVID-19 prognosis and progress, public health experts must disseminate accurate information to promote healthy behavior modification and increase receptiveness to smoking cessation advice, especially targeted at vulnerable individuals such as current smokers and former smokers with a risk of relapse $\mathrm{e}^{25}$.

The findings of this study also highlight the importance of expanding programs that promote smoking cessation for smokers and prevent relapse for former smokers or smoking initiation for never smokers. Investing in more smoking cessation resources can help prevent an increase in smoking behavior as a result of the challenges brought on by the pandemic ${ }^{26,27}$. In addition, for individuals who have been motivated by COVID-19 to make healthier choices, it is important to capitalize on this positive outcome to support them in reducing their smoking behavior. Given social distancing and the increased use of virtual communication, digital health interventions such as social media campaigns and telemedicine services are particularly suited to enhance smoking cessation during the pandemic ${ }^{28,29}$.

\section{Strengths and limitations}

A strength of our study is the fact that it was conducted in the immediate months following the onset of the pandemic and is one of the first studies assessing the impact of COVID-19 on smoking behavior and beliefs.

The main limitation of our study is the use of a convenience sample from the AUB community. This is reflected by a disproportionally younger, English-speaking, and educated population. While this sample was representative of the AUB community, it is not representative of the entire Lebanese population, which limits the 
generalization of the results. In addition, the survey had a low response rate which led to small sample size. Another limitation is due to the self-report nature of the survey, which makes it susceptible to social desirability bias. Further studies with more representative samples are needed to confirm our findings.

\section{CONCLUSIONS}

The current COVID-19 outbreak has resulted in unexpected alterations in routine and changes in health behaviors. The impact of the pandemic on smoking behavior and beliefs in one academic institution is investigated in this exploratory study. A quarter of all participants said they had changed their smoking habits, with an equal percentage saying they had increased or decreased their smoking. Future research is needed to look into changes in smoking behavior in a more representative group. Experts in public health must be vigilant. To convey accurate information about smoking and COVID-19, as well as expand access to smoking cessation programs, public health experts must leverage digital health interventions that were heavily used during this pandemic.

\section{REFERENCES}

1. Romani M, Nakkash R, Jawhar S, Salloum RG. Implementation of a free smoking-cessation program in a Lebanese academic medical center. Tob Induc Dis. 2020;18(September):1-5. doi:10.18332/tid/125916

2. Lebanese Ministry of Information. Coronavirus statistics. Updated June 23, 2021. Accessed October 24, 2021. https://corona.ministryinfo.gov.lb/

3. Flesia L, Monaro M, Mazza C, et al. Predicting Perceived Stress Related to the Covid-19 Outbreak through Stable Psychological Traits and Machine Learning Models. J Clin Med. 2020;9(10):3350. doi:10.3390/jcm9103350

4. MacMillan T, Corrigan MJ, Coffey K, Tronnier CD, Wang D, Krase K. Exploring Factors Associated with Alcohol and/or Substance Use During the COVID-19 Pandemic. Int J Ment Health Addict. 2021. doi:10.1007/s11469-020-00482-y

5. Mucci F, Mucci N, Diolaiuti F. LOCKDOWN AND ISOLATION: PSYGHOLOGICAL ASPECTS OF COVID-19 PANDEMIC IN THE GENERAL POPULATION. Clinical Neuropsychiatry: Journal of Treatment Evaluation. 2020;17(2):63-64. doi:10.36131/CN20200205

6. Pfefferbaum B, North CS. Mental Health and the Covid-19 Pandemic. N Engl J Med. 2020;383(6):510-

\section{2. doi:10.1056/NEJMp2008017}

7. Casagrande M, Favieri F, Tambelli R, Forte G. The enemy who sealed the world: effects quarantine due to the COVID-19 on sleep quality, anxiety, and psychological distress in the Italian population. Sleep Med. 2020;75:1220. doi:10.1016/j.sleep.2020.05.011

8. Di Renzo L, Gualtieri P, Pivari F, et al. Eating habits and lifestyle changes during COVID-19 lockdown: an Italian survey. J Transl Med. 2020;18(1):229. doi:10.1186/s12967-020-02399-5

9. Patwardhan P. COVID-19: Risk of increase in smoking rates among England's 6 million smokers and relapse among England's 11 million ex-smokers. BJGP Open. 2020;4(2):bjgpopen20X101067. doi:10.3399/bjgpopen20X101067

10. Bommele J, Hopman P, Walters BH, et al. The doubleedged relationship between COVID-19 stress and smoking: Implications for smoking cessation. Tob Induc Dis. 2020;18(July):1-5. doi:10.18332/tid/125580

11. Klemperer EM, West JC, Peasley-Miklus C, Villanti AC. Change in Tobacco and Electronic Cigarette Use and Motivation to Quit in Response to COVID-19. Nicotine Tob Res. 2020;22(9):1662-1663. doi:10.1093/ntr/ntaa072

12. Global Adult Tobacco Survey Collaborative Group. Tobacco Questions for Surveys: A Subset of Key Questions from the Global Adult Tobacco Survey (GATS). 2nd ed. Centers for Disease Control and Prevention; 2011. Accessed November 30, 2021. https://apps.who.int/iris/ bitstream/handle/10665/87331/9789241500951_eng. pdf? sequence $=1 \&$ isAllowed $=y$

13. Richards J, Stipelman BA, Bornovalova MA, Daughters S, Sinha R, Lejuez CW. Biological Mechanisms Underlying the Relationship between Stress and Smoking: State of the Science and Directions for Future Work. Biol Psychol. 2011;88(1):1-12. doi:10.1016/j.biopsycho.2011.06.009

14. Twyman L, Bonevski B, Paul C, Bryant J. Perceived barriers to smoking cessation in selected vulnerable groups: a systematic review of the qualitative and quantitative literature. BMJ Open. 2014;4(12):e006414. doi:10.1136/bmjopen-2014-006414

15. Stubbs B, Veronese N, Vancampfort D, et al. Perceived stress and smoking across 41 countries: A global perspective across Europe, Africa, Asia and the Americas. Sci Rep. 2017;7(1):7597. doi:10.1038/s41598-017-07579-w

16. Lawless MH, Harrison KA, Grandits GA, Eberly LE, Allen SS. Perceived stress and smokingrelated behaviors and symptomatology in male and female smokers. Addict Behav. 2015;51:80-83. doi:10.1016/j.addbeh.2015.07.011

17. Chertok IRA. Perceived risk of infection and smoking behavior change during COVID-19 in Ohio. Public Health Nurs. 2020;37(6):854-862. doi:10.1111/phn.12814

18. Roberts NJ, Kerr SM, Smith SM. Behavioral Interventions Associated with Smoking Cessation in the Treatment of Tobacco Use. Health Serv Insights. 2013;6:79-85. 
doi:10.4137/HSI.S11092

19. Yang H, Ma J. How the COVID-19 pandemic impacts tobacco addiction: Changes in smoking behavior and associations with well-being. Addict Behav. 2021;119:106917. doi:10.1016/j.addbeh.2021.106917

20. Yach D. Tobacco Use Patterns in Five Countries During the COVID-19 Lockdown. Nicotine Tob Res. 2020;22(9):1671-1672. doi:10.1093/ntr/ntaa097

21. Elling JM, Crutzen R, Talhout R, de Vries H. Tobacco smoking and smoking cessation in times of COVID-19. Tob Prev Cessat. 2020;6(July):1-5. doi:10.18332/tpc/122753

22. Chen DTH. The psychosocial impact of the COVID-19 pandemic on changes in smoking behavior: Evidence from a nationwide survey in the UK. Tob Prev Cessat. 2020;6(October):1-5. doi:10.18332/tpc/126976

23. Kamiński M, Muth A, Bogdański P. Smoking, Vaping, and Tobacco Industry During COVID-19 Pandemic: Twitter Data Analysis. Cyberpsychol Behav Soc Netw. 2020;23(12):811-817. doi:10.1089/cyber.2020.0384

24. Klayman J, Ha Y-w. Confirmation, disconfirmation, and information in hypothesis testing. Psychol Rev. 1987;94(2):211-228. doi:10.1037/0033-295X.94.2.211

25. Geldsetzer P. Use of Rapid Online Surveys to Assess People's Perceptions During Infectious Disease Outbreaks: A Cross-sectional Survey on COVID-19. J Med Internet Res. 2020;22(4):e18790. doi:10.2196/18790

26. Lang AE, Yakhkind A. Coronavirus Disease 2019 and Smoking: How and Why We Implemented a Tobacco Treatment Campaign. Chest. 2020;158(4):1770-1776. doi:10.1016/j.chest.2020.06.013

27. Leonel ACLS, Martelli-Junior H, Bonan PRF, Kowalski LP, da Cruz Perez DE. COVID-19, head and neck cancer, and the need of training of health students and practitioners regarding to tobacco control and patient counseling. Oral Oncol. 2020;106:104739. doi:10.1016/j.oraloncology.2020.104739

28. Schumacher S, Kent N. 8 charts on internet use around the world as countries grapple with COVID-19. Pew Research Center. April 2, 2020. Accessed November 30, 2021. https://www.pewresearch.org/fact-tank/2020/04/02/8charts-on-internet-use-around-the-world-as-countriesgrapple-with-covid-19/ 2020

29. Cheung KL, Wijnen B, de Vries H. A Review of the Theoretical Basis, Effects, and Cost Effectiveness of Online Smoking Cessation Interventions in the Netherlands: A Mixed-Methods Approach. J Med Internet Res. 2017;19(6):e230. doi:10.2196/jmir.7209

\section{CONFLICTS OF INTEREST}

The authors have completed and submitted the ICMJE Form for Disclosure of Potential Conflicts of Interest and none was reported.

\section{FUNDING}

There was no source of funding for this research.

ETHICAL APPROVAL AND INFORMED CONSENT

The study was reviewed by the AUB Institutional Review Board (IRB) ethical committee and considered exempt (IRB ID SBS-2020-0236). Participants of the survey provided informed consent.

DATA AVAILABILITY

The data supporting this research are available from the authors on reasonable request.

PROVENANCE AND PEER REVIEW

Not commissioned; externally peer reviewed. 